\title{
High prevalence of anti-hepatitis B virus serological markers in patients with hepatitis C virus related chronic liver disease in Japan
}

H Marusawa, Y Osaki, T Kimura, K Ito, Y Yamashita, T Eguchi, M Kudo, Y Yamamoto, H Kojima, H Seno, F Moriyasu, T Chiba

\author{
Division of \\ Gastroenterology and \\ Hepatology, \\ Department of \\ Medicine, \\ Postgraduate School of \\ Medicine, Kyoto \\ University, Kyoto, \\ Japan \\ H Marusawa \\ H Seno \\ F Moriyasu \\ T Chiba
}

Department of Gastroenterology, Osaka Red Cross

Hospital, Osaka, Japan

Y Osaki

T Kimura

Department of

Gastroenterology,

Shizuoka General

Hospital, Shizuoka,

Japan

K Ito

H Kojima

Department of

Gastroenterology,

Kishiwada City

Hospital, Osaka, Japan

Y Yamashita

Department of Gastroenterology,

Kitano Hospital,

Osaka, Japan

T Eguchi

Department of

Gastroenterology,

Kobe City General

Hospital, Hyogo, Japan

M Kudo

Department of

Gastroenterology,

Takatsuki General

Hospital, Osaka, Japan

Y Yamamoto

Correspondence to:

Dr T Chiba, Department of

Gastroenterology and

Hepatology, Department of

Medicine, Postgraduate

School of Medicine, Kyoto

University, 54 Kawara-cho,

Shogoin, Sakyo-ku, Kyoto

606-8507, Japan.

Accepted for publication

17 February 1999
Abstract

BackgroundlAims-Evidence is accumulating that hepatitis $B$ virus (HBV) is present in patients who are hepatitis $B$ surface antigen negative but have antibody to hepatitis $B$ core antigen (antiHBc). Furthermore, recent studies have shown that patients with hepatocellular carcinoma who have antibody to hepatitis $C$ virus (HCV) often possess $\mathrm{HBV}$ related serological markers. Data on the seroprevalence of $\mathrm{HBV}$ infection in patients with HCV related chronic liver disease were collected to evaluate the significance of the presence of antibodies to $\mathrm{HBV}$.

Methods-The prevalence of $\mathrm{HBV}$ related serological markers was analysed in a total of 2014 Japanese patients with $\mathrm{HCV}$ infection. The control group comprised 352 subjects without liver disorder.

Results-A large number of patients $(49.9 \%)$ with HCV related chronic liver disease including hepatocellular carcinoma were positive for anti-HBc. In addition, the prevalence of anti-HBc closely correlated with the clinical stage of the liver disease. There was no relation between a past history of blood transfusion and the prevalence of anti-HBc. Notably, anti-HBc was the only serological marker for $\mathrm{HBV}$ infection in a significant number of patients with $\mathrm{HCV}$ related chronic liver disease $(24.1 \%)$.

Conclusions-Our data provide further evidence for the high prevalence of antiHBc in patients with HCV related chronic liver disease, particularly those with hepatocellular carcinoma, suggesting that HBV infection, probably including latent infection, may play an important role in carcinogenesis in these patients.

(Gut 1999;45:284-288)

Keywords: hepatitis B virus; anti-HBc; hepatitis C virus; hepatocellular carcinoma

Hepatitis $\mathrm{C}$ virus (HCV) has been known to be a causative agent of chronic liver disease, and this persistent viral infection is closely linked to the development of primary hepatocellular carcinoma (HCC). ${ }^{1-4}$ Although the mechanism of carcinogenesis in patients with $\mathrm{HCV}$ infection has not been clarified, several investigators have recently shown that anti-HCV positive patients with HCC also often have hepatitis B virus (HBV) related antibodies in their serum, ${ }^{5-9}$ suggesting that HBV infection may be involved in the development of HCC in patients who are anti-HCV positive. On the other hand, we have recently shown that the HBV genome is invariably present in the liver tissue of healthy donors who are hepatitis B surface antigen (HBsAg) negative but positive for antibody to hepatitis B core antigen (anti-HBc).${ }^{10}$ Moreover, many previous studies have documented that HBV genomes are often detected in the liver tissue of patients even if they are negative for HBsAg. ${ }^{11-21}$ These data suggest that HBV infection may often be observed in the liver of subjects who are positive for anti-HBV markers, and therefore it is possible that a considerable number of patients who have hitherto been regarded as having "HCV related chronic liver disease" may also have latent HBV infection. Thus, we studied 2014 patients in Japan with HCV related chronic liver disease, including those with HCC, in order to look for serological markers of HBV infection. We discuss the significance of the presence of anti-HBV markers in patients with HCV infection in the development of HCC.

\section{Patients and methods}

PATIENTS

Patients with HCV related chronic liver disease who visited Kyoto University or its affiliated hospitals in Japan between April 1996 and March 1997 were considered to be eligible for this study. Of these, all patients fulfilling the following criteria were randomly selected and included: (a) serum anti-HCV positive at entry; (b) serum HBsAg negative at entry; (c) information on other serological markers of HBV available. These cases were classified into the following three groups on the basis of clinical findings, blood chemistry, ultrasonography, angiography, and/or histological findings of specimens obtained by fine needle biopsy and/or at operation: chronic hepatitis $(\mathrm{CH})$, liver cirrhosis (LC), and HCC. Information on cigarette smoking, alcohol consumption, and medical and family history was carefully obtained at the time of enrollment through interviews by the doctors in charge and the experienced public health nurses, and if the information from any of the patients was unre-

Abbreviations used in this paper: $\mathrm{HCV}$, hepatitis $\mathrm{C}$ virus; $\mathrm{HBV}$, hepatitis $\mathrm{B}$ virus; $\mathrm{HBc}$, hepatitis $\mathrm{B}$ core; HCC, hepatocellular carcinoma; HBsAg, hepatitis B surface antigen; $\mathrm{CH}$, chronic hepatitis; LC, liver cirrhosis. 
Table 1 Characteristics of patients with hepatitis $C$ virus related chronic liver disease

\begin{tabular}{lllll}
\hline & CH & LC & HCC & Total \\
\hline No of patients & 973 & 430 & 611 & 2014 \\
Age (years) & $59.1(0.6)$ & $60.3(0.4)$ & $65.8(0.3)^{\star}$ & $61.4(0.3)$ \\
Sex (M/F) & $522 / 451$ & $210 / 220$ & $475 / 136^{\star}$ & $1207 / 807$ \\
Daily drinkers (\%) & 30.7 & 29.4 & $45.5^{\star}$ & 34.8 \\
Smoking index 400 (\%) & 25.4 & 22.7 & $39.7^{\star}$ & 29.2 \\
Past history of blood transfusion (\%) & 38.0 & 36.1 & 30.6 & 35.4
\end{tabular}

Age is given as mean (SE). Values for drinking, smoking, and past history of blood transfusion represent percentages of the total number of patients in each group. $\mathrm{CH}$, chronic hepatitis; LC, liver cirrhosis; HCC, hepatocellular carcinoma.

${ }^{\star}$ Significantly higher than LC or $\mathrm{CH}$ group $(\mathrm{p}<0.01)$.

liable or unclear, these patients were excluded from the evaluation. Drinking habits were classified into the following two grades: (a) non-drinkers and occasional drinkers; $(b)$ daily drinkers. Daily drinkers were defined as those drinking alcohol 5 days/week for 15 years. A smoking index was obtained by multiplying the average number of cigarettes smoked a day by the total number of years of smoking. Accordingly, smoking habits were also classified into the following two grades based on the smoking index: (a) non-smokers and light smokers (smoking index <400); (b) heavy smokers (smoking index 400 or above). In all cases, the presence or absence of anti-HBV antibodies in the serum was examined. Using these procedures, 2014 patients were finally enrolled into the study. For the control group, a total of 352 subjects were randomly selected with the following restrictions: (a) a visit during the same period to the same hospital; $(b)$ no liver disease confirmed by blood chemistry and ultrasonography; (c) anti-HCV negative at entry.

\section{SEROLOGICAL EVALUATION}

The tests for antibody to $\mathrm{HBsAg}$ (anti-HBs) and anti-HBc in patient sera were by enzyme immunoassay and/or radioimmunoassay using commercially available kits (Dainabott, Tokyo, Japan). Serum HBV DNA was determined by polymerase chain reaction assay as described previously. ${ }^{10}$ The diagnosis of HCV infection was made by the presence in the serum of anti$\mathrm{HCV}$, as assessed by second or third generation assays.

\section{STATISTICAL ANALYSES}

The $\chi^{2}$ test was used to compare frequencies entered in 2 by 2 contingency tables, and all $p$ values were based on two sided tests. For the subgroup analyses, odds ratios and $95 \%$ confidence intervals were determined. All calculations were performed using SAS software (SAS Institute Inc).

Table 2 Anti-HBV serological markers in different clinical stages of hepatitis $C$ virus related chronic liver disease

\begin{tabular}{lllll}
\hline & CH & LC & HCC & Total \\
\hline Anti-HBs positive & 25.6 & 28.1 & $35.4^{\star}$ & 29.1 \\
$\begin{array}{l}\text { Anti-HBc positive } \\
\text { Age (years) }\end{array}$ & 43.8 & 49.8 & $59.4^{\star}$ & 49.9 \\
$\quad<60$ & $36.3(160 / 441)$ & $41.8(46 / 110)$ & $58.9^{\star}(56 / 95)$ & $40.6(262 / 646)$ \\
$\geqslant 60$ & $50.0(266 / 532)$ & $52.8(169 / 320)$ & $59.5^{\star}(307 / 516)$ & $54.2(742 / 1368)$ \\
\hline
\end{tabular}

Values represent percentages of the total number of patients in each group. Values in parentheses show the actual number of patients (patients with anti-HBc positive/total patients). HBV, hepatitis B virus; $\mathrm{CH}$, chronic hepatitis; LC, liver cirrhosis; HCC, hepatocellular carcinoma; anti-HBs, antibody to hepatitis B surface antigen; anti-HBc, antibody to hepatitis B core antigen.

* Significantly higher than LC or CH group $(\mathrm{p}<0.01)$.

\section{Results}

Table 1 summarises the clinical features of the enrolled patients. A total of 2014 patients were considered to be eligible for the study. Of these, 973 had a diagnosis of $\mathrm{CH}, 430$ had LC, and 611 had HCC. The mean age of the patients with HCC was significantly higher than that of those with $\mathrm{CH}$ or LC (65.8 v 59.1 and 60.3 respectively). The proportion of women patients was much smaller for $\mathrm{HCC}$ than $\mathrm{CH}$ or LC $(22.3 \% v 46.4$ and $51.2 \%$ respectively). Both the smoking and alcohol indices were significantly higher in patients with HCC than in those with either $\mathrm{CH}$ or LC in accordance with many previous reports. ${ }^{82-24}$ At the time of enrollment, all patients were interviewed about their previous history; of the 1775 patients whose information was considered to be reliable, $629(35.4 \%)$ had received a blood transfusion. The percentage of patients with a history of blood transfusion was not significantly different among patients with $\mathrm{CH}, \mathrm{LC}$, and HCC (38.0, 36.1, and 30.6\% respectively). Information on the history of intravenous drug use and previous $\mathrm{HBV}$ vaccination was also obtained at enrollment, and a total of 12 and eight patients respectively had such histories. However, no association was found between these factors and the clinical stage of liver disease.

Table 2 shows serological status with regard to anti-HBV antibodies. A total of 52 anti-HCV positive patients with $\mathrm{HBV}$ marker $(12 \mathrm{CH}, 15$ LC, and 25 HCC) were selected randomly and examined for the presence of circulating HBV DNA sequences, as detected by amplification of the $S$ region. ${ }^{10}$ Serum HBV DNA was not present in any of the patients. Of those with HCV related chronic liver disease, 29.1\% were positive for anti-HBs, a value that is clearly higher than that observed in the general population. ${ }^{25}$ More significantly, a total of 1004 patients $(49.9 \%)$ were positive for the anti$\mathrm{HBc}$ antibody; again, this rate is higher than that observed in the general population. ${ }^{25}$ The proportion of patients who were positive for the anti-HBs and anti-HBc increased with progression of the liver disease. In particular, the percentage of patients testing positive for anti$\mathrm{HBs}$ and the percentage positive for anti-HBc were both significantly higher in cases of HCC than in cases of either $\mathrm{CH}$ or LC. It is widely recognised that the prevalence of anti-HBV serological markers increases with age, and the mean age of patients with HCV related chronic liver disease is generally high. ${ }^{23}{ }^{24}$ Thus it may be that the high prevalence of anti-HBV serological markers in these patients is merely a reflection of their advanced age. In order to clarify this, subjects without HCV infection were also tested for anti-HBc antibody, and compared with anti-HCV positive patients (table 3). Anti-HBc was detected in 44 of 352 $(12.2 \%)$ controls and was distributed around $10 \%$ in any age group. This result was consistent with a previous report on blood donors in Japan. ${ }^{25}$ Even after matching for age, the rate of seropositivity for anti-HBc in $\mathrm{HCV}$ related chronic liver disease was significantly higher than that in the control of any age group. Fur- 
Table 3 Anti-HBc positivity in patients with hepatitis $C$ virus (HCV) related chronic liver disease and control patients matched by age

\begin{tabular}{lll}
\hline Age (years) & Control & $\begin{array}{l}\text { Anti-HCV positive } \\
\text { chronic liver disease }\end{array}$ \\
\hline $20-29$ & 5.4 & $9.1^{\star}$ \\
$30-39$ & 10.8 & $27.2^{\star}$ \\
$40-49$ & 11.8 & $41.5 \dagger$ \\
$50-59$ & 12.6 & $43.6 \dagger$ \\
$\geqslant 60$ & 14.8 & $54.2 \dagger$ \\
\hline
\end{tabular}

Values represent percentages of the total number of patients in each group. Anti-HBc, antibody to hepatitis B core antigen.

*Significantly higher than control $(p<0.05)$.

†Significantly higher than control $(\mathrm{p}<0.01)$

thermore, in order to assess the influence of the difference in mean age between HCC and non-HCC groups on the rate of anti-HBc positivity, the anti-HCV positive patients were split into two age groups (table 2). The positive rate for anti-HBc in the HCC group was found to be significantly higher than that in the $\mathrm{CH}$ and LC groups not only in patients under the age of 60 years, but also in those over the age of 60 years. The difference was more pronounced in the younger age group.

To exclude the influence of other factors on the increased positivity of anti-HBc in patients with HCC, the subgroup analyses by sex, alcohol intake, cigarette smoking, and history of blood transfusion were performed between the $\mathrm{CH}$ and HCC groups (table 4). We confirmed that the odds ratios for each factor were similar in each subgroup and these factors have no effect on seropositivity for anti- $\mathrm{HBc}$ in these patients. Furthermore, there were also no interactive effects of the history of intravenous drug abuse on the high prevalence of anti-HBc in the HCC group (data not shown).

According to a previous report, most blood donors with anti-HBc are usually also anti-HBs positive, while only $2.8 \%$ of patients are positive only for anti-HBc. ${ }^{25}$ In contrast with the pattern seen in healthy blood donors, there were many patients with $\mathrm{HCV}$ infection who were positive only for anti-HBc but negative for anti-HBs. In fact, $24.1 \%$ of the total number of patients with $\mathrm{HCV}$ related chronic liver disease had anti-HBc in the absence of anti-HBs. In contrast, the positivity of anti-HBs alone was $4.6 \%$ among anti-HCV positive patients, and this group included all eight individuals who had received an HBV vaccination.

It may be speculated that the high prevalence of anti-HBV serological markers in patients with $\mathrm{HCV}$ infection is due to the fact that many

Table 4 Odds ratios of anti-HBc positivity and hepatocellular carcinoma with hepatitis $C$ virus infection

\begin{tabular}{lll}
\hline Subgroup & Odds ratio & 95\% Confidence interval \\
\hline Sex & 1.77 & 1.37 to 2.27 \\
$\quad$ Male & 1.84 & 1.25 to 2.71 \\
$\quad$ Female & 1.48 & 1.10 to 1.98 \\
Alcohol intake & 1.84 & 1.27 to 2.67 \\
$\quad$ Nondrinkers and occasional drinkers & 1.58 & 1.18 to 2.11 \\
$\quad$ Daily drinkers & 2.10 & 1.39 to 3.17 \\
Cigarette smoking & & \\
$\quad$ Nonsmokers and light smokers & 1.79 & 1.22 to 2.62 \\
$\quad$ Heavy smokers & 1.64 & 1.25 to 2.14 \\
$\quad$ Past history of blood transfusion & \\
$\quad$ Positive & Negative &
\end{tabular}

Comparison was performed between patients with hepatocellular carcinoma and chronic hepatitis. Anti-HBc, antibody to hepatitis B core antigen. of them have had a blood transfusion in the past. Therefore, we evaluated the possible relation between a history of blood transfusion and the positive rate for anti-HBc in our study population. The positive rate for the anti-HBc was $46.9 \%$ and $50.9 \%$ in patients with and without a history of blood transfusion respectively. Thus, a history of blood transfusion cannot account for the higher rate of anti-HBV serological markers in patients with $\mathrm{HCV}$ infection. Similarly, other risk factors predisposing to viral transmission such as history of intravenous drug use or chance of sexual transmission were not different between anti-HBc positive and negative patients.

\section{Discussion}

In this study, we found that the prevalence of anti-HBc is almost $50 \%$ in patients with $\mathrm{HCV}$ related chronic liver disease, which is significantly higher than that reported in healthy blood donors at a blood centre in Japan. ${ }^{25}$ It is also higher than that observed in our control group without liver disease $(12.2 \%)$. Several previous reports have already shown a high prevalence of anti-HBV serological markers in HCV infected patients. ${ }^{5-9}$ However, most of the previous reports have mainly focused on patients with HCC, and moreover have not assessed the anti-HBV serological status in relation to age. It is known that the prevalence of anti-HBV serological markers increases with age. Moreover, the mean age of patients with $\mathrm{HCV}$ related chronic liver disease is generally high, ${ }^{23}$ raising the possibility that the high prevalence of anti-HBV markers in $\mathrm{HCV}$ related chronic liver disease found in this study merely reflects their advanced age. Indeed, our patients with anti-HCV are older than the blood donors in the previous report. Therefore we selected subjects without HCV infection as a control group in order to compare the rates of seropositivity in age matched groups. This showed that the prevalence of anti-HBV serological markers was higher in patients with HCV related chronic liver disease than in control subjects irrespective of age.

It is also known that many patients with antiHCV have a history of blood transfusion. ${ }^{23}{ }^{24}$ Thus it could be postulated that the high prevalence of anti-HBV markers in patients with $\mathrm{HCV}$ infection is merely attributable to having received a blood transfusion in the past. In this study, however, we found that the percentage of patients with a history of blood transfusion was not different in those with and without anti-HBc. Moreover, although the prevalence of anti-HBc increases as the liver disease progresses, the percentage of patients with a history of blood transfusion was not different among patients with $\mathrm{CH}, \mathrm{LC}$, and HCC. Taking the results together, we could not find any relation between a previous history of blood transfusion and being positive for anti-HBc. In addition, we confirmed that other factors, such as sex, smoking, and drinking, had no influence on the seropositivity for antiHBc. No remarkable differences were observed between the anti-HBc positive and negative group in the prevalence of histories predispos- 
ing to viral infection such as intravenous drug use. Thus, by analysing a large number of diverse patients including those with HCC, $\mathrm{CH}$, and LC in Japan, we have clearly shown that the prevalence of anti-HBV serological markers is high in $\mathrm{HCV}$ related chronic liver disease even when other factors such as a past history of blood transfusion and differences in age are excluded.

It has been generally accepted that patients who are negative for $\mathrm{HBsAg}$, but positive for anti-HBs and/or anti-HBc (low titre), have previously had transient HBV infection. However, it has been recently shown that traces of HBV are often detectable in the blood for many years after clinical recovery from acute hepatitis despite the presence of serum antibodies against the HBV and HBV specific cytotoxic T lymphocytes. ${ }^{26} 27$ Furthermore, we have recently shown the transmission of $\mathrm{HBV}$ from healthy donors who were negative for $\mathrm{HBsAg}$ but positive for anti-HBc (low titre) to recipients in living related liver transplantation..$^{10}$ In addition, Koike et $a l^{621}$ have reported that clonally integrated HBV DNA sequences were identified at a high rate in patients with anti-HCV positive HCC who were seronegative for HBsAg. Taking these results together, it is strongly suggested that seronegativity for HBsAg does not exclude the existence of HBV DNA, and that HBV is often present in the liver tissue of patients who are positive for anti$\mathrm{HBc}$ (low titre) even in the absence of HBsAg. ${ }^{11-21}{ }^{28}$ Thus it is conceivable that the patients with $\mathrm{HCV}$ related chronic liver disease who are positive for anti-HBc may have dual sustained infection with both HBV and HCV in the liver.

In this study, we found a strong correlation between the clinical stage of liver disease and the prevalence of anti-HBV antibodies. Indeed, the prevalence of the anti-HBc in patients with HCC was about $60 \%$, which was significantly higher than that observed in $\mathrm{CH}$ and LC. These results are in accordance with several previous reports, ${ }^{5-9}$ and suggest that $\mathrm{HBV}$ co-infection may be involved in hepatocarcinogenesis in patients with HCV related chronic liver disease. In contrast with our data, however, there is one study which showed that the rate of positivity for anti-HBV markers in patients with anti-HCV positive HCC was not high. ${ }^{29}$ The reasons for these discrepant findings are unclear. They may be due to geographical difference, even though both studies were carried out in Japanese patients. However, it is more likely to be attributable to the different methods of evaluation for $\mathrm{HBV}$ infection. HBV serostatus was evaluated mainly by measuring anti-HBs status in the previous study. Our data on HBV transmission in liver transplantation, however, suggest that it is more important to test for anti$\mathrm{HBc}$ rather than anti-HBs to predict latent $\mathrm{HBV}$ infection. ${ }^{10}$

In relation to the importance of anti-HBc in evaluating latent $\mathrm{HBV}$ infection, an interesting observation in this study is the characteristic pattern of anti-HBV serological status in patients with HCV infection. Generally, healthy blood donors who are positive for anti-
$\mathrm{HBc}$ also tend to be positive for anti-HBs. In this study, however, we found that as many as $24.1 \%$ of the patients with $\mathrm{HCV}$ related chronic liver disease were positive for anti-HBc but negative for anti-HBs. The reason for the difference in anti-HBV serological status between healthy blood donors and patients with $\mathrm{HCV}$ related chronic liver disease is unclear at present. ${ }^{30}$ It may be that HBV infection occurs in anti-HCV positive patients at a younger age than the healthy population, because anti-HBc remains detectable long after anti-HBs is no longer detectable. ${ }^{31}$ However, an alternative explanation may be that co-existing HCV protein has a negative effect on the synthesis of $\mathrm{HBsAg}$, with a resulting decrease in anti-HBs production. Indeed, a previous study has shown an inverse relation between $\mathrm{HBV}$ and $\mathrm{HCV}$ replication. ${ }^{32}{ }^{33}$ In another report, $\mathrm{HCV}$ core protein has been shown to dramatically suppress HBsAg synthesis. ${ }^{34}$

In conclusion, this study has clearly shown a high prevalence of anti-HBc in HCV related chronic liver disease, including not only HCC but also $\mathrm{CH}$ and LC. Considering the accumulating evidence showing that the seropositivity of anti-HBc is often associated with sustained hepatic infection with $\mathrm{HBV}$, our data suggest the possibility that HBV infection, including latent infection, may be important in the development of HCC in patients with $\mathrm{HCV}$ related chronic liver disease.

The following institutions and investigators also participated in the study: Dr N Kitajima, Miki City Hospital; Dr K Nishina, Kurashiki Central Hospital; Dr T Suyama, Shiga Medical Center for Adults; Dr M Nabeshima, Kyoto Katsura Hospital; Dr S Ono, Ako Municipal Hospital; Dr O Nishida, Otsu Red-Cross Hospital; Dr H Komori, Nishi-Kobe Medical Center; Dr T Tamada, Takatsuki Red Cross Hospital. The work was supported by Grants-in-Aid for Scientific and Cancer was supported by Grants-in-Aid for Scientific and Cancer Research from the Ministry of Education, Science and Culture, a Grant from Ministry of Health and Welfare, Japan, and a JSPS-RFTF97I00201)

1 Choo QL, Kuo G, Weiner A, et al. Isolation of a cDNA clone derived from a blood-borne non-A non-B viral hepatitis derived from a blood-borne non-A

2 Kuo G, Choo QL, Alter HJ, et al. An assay for circulating antibodies to a major etiologic virus of human non-A non-B hepatitis. Science 1989;244:362-4.

3 Ohkoshi S, Kojima H, Tawaraya H, et al. Prevalence of antibody against non-A non-B hepatitis virus in Japanese patients with hepatocellular carcinoma. Fpn $\mathcal{f}$ Cancer Res 1990;81:550-3.

4 Liang TJ, Jeffers LJ, Reddy KR, et al. Viral pathogenesis of hepatocellular carcinoma in the United States. Hepatology 1993;18:1326-33.

5 Nishioka K, Watanabe J, Furuta S, et al. A high prevalence of antibody to the hepatitis $\mathrm{C}$ virus in patients with hepatocellular carcinoma in Japan. Cancer 1991;67:429-33.

6 Koike K, Nakamura Y, Kobayashi M, et al. Hepatitis B virus DNA integration frequently observed in the hepatocellular carcinoma DNA of hepatitis $\mathrm{C}$ virus-infected patients. Int $\mathcal{f}$ Oncol 1996;8:78 of

7 Saito I, Miyamura T, Ohbayashi A, et al. Hepatitis C virus infection is associated with the development of hepatocellular carcinoma. Proc Natl Acad Sci USA 1990;87:6547-9.

8 Chiba T, Matsuzaki Y, Abei M, et al. The role of hepatitis B virus infection and heavy smoking in hepatitis $\mathrm{C}$ virusrelated hepatocellular carcinoma. Am f Gastroenterol 1996; 91:1195-203

9 Ruiz J, Sangro B, Cuende JI, et al. Hepatitis B and C viral infections in patients with hepatocellular carcinoma. Hepatology 1992;16:637-41

10 Uemoto S, Sugiyama K, Marusawa H, et al. Transmission of hepatitis B virus from hepatitis B core antibody-positive donors in living related liver transplants. Transplantation 1998;65:494-9.

11 Brechot C, Pourcel C, Louise A, et al. Presence of integrated hepatitis B virus DNA sequences in cellular DNA of human hepatocellular carcinoma. Nature 1980;286:533-5. 12 Brechot C, Degos F, Lugassy C, et al. Hepatitis B virus DNA in patients with chronic liver disease and negative
tests for hepatitis B surface antigen. $N$ Engl $f$ Med 1985;312:270-6. 
13 Paterlini P, Gerken G, Nakajima E, et al. Polymerase chain reaction to detect hepatitis $\mathrm{B}$ virus DNA and RNA sequences in primary liver cancer from patients negative for

4 Lai M-Y, Chen P-J, Yang P-M, et al. Identification and char-

4 Lai M-Y, Chen P-J, Yang P-M, et al. Identification and char-
acterization of intrahepatic hepatitis B virus DNA in acterization of intrahepatic hepatitis B virus DNA in HBsAg-seronegative patients with chronic liver disease and hepatocellul.

15 Blum HE, Liang TJ, Galun E, et al. Persistence of hepatits B viral DNA after serological recovery from hepatitis B virus infection. Hepatology 1991;14:56-62

16 Kuhns M, Mcnamara A, Mason A, et al. Serum and liver hepatitis B virus DNA in chronic hepatitis B after sustained loss of surface antigen. Gastroenterology 1992;103:1649-56.

17 Fong TL, Di Bisceglie AM, Gerber MA, et al. Persistence of hepatitis B virus DNA in the liver after loss of HBsAg in chronic hepatitis B. Hepatology 1993;18:1313-18.

18 Michalak TI, Pasquinelli C, Guilhot S, et al. Hepatitis B virus persistence after recovery from acute viral hepatitis. $\mathcal{F}$ virus persistence after reco

19 Mitri MSD, Poussin K, Baccarini P, et al. HCV-associated liver cancer without cirrhosis. Lancet 1995;345:413-15.

20 Edamoto Y, Tani M, Kurata T, et al. Hepatitis $C$ and B virus infections in hepatocellular carcinoma. Cancer 1996;77 $1787-91$

21 Urashima T, Saigo K, Kobayashi S, et al. Identification of hepatitis $\mathrm{B}$ virus integration in hepatitis $\mathrm{C}$ virus-infected hepatocellular carcinoma tissues. F Hepatol 1997;26:771-8.

22 Yu M-W, You S-L, Chang A-S, et al. Association between hepatitis $\mathrm{C}$ virus antibodies and hepatocellular carcinoma in Taiwan. Cancer Res 1991;51:5621-5.

23 Tsukuma H, Hiyama T, Tanaka S, et al. Risk factors for hepatocellular carcinoma among patients with chronic liver disease. N Engl f Med 1993;328:1797-801.

24 Ikeda K, Saitoh S, Koida I, et al. A multivariate analysis of risk factors for hepatocellular carcinogenesis: a prospective observation of 795 patients with viral and alcoholic cirrhosis. Hepatology 1993;18:47-53.

25 Iizuka H, Ohmura K, Ishijima A, et al. Correlation between anti-HBc titers and HBV DNA in blood units without detectable HBsAg. Vox Sang 1992;63:107-11.

26 Rehermann B, Ferrari C, Pasquinelli C, et al. The hepatitis $B$ virus persists for decades after patients recovery from acute viral hepatitis despite active maintenance of a cytotoxic T-lymphocyte response. Nat Med 1996;2:1104-8.

27 Penna J, Artini M, Cavalli A, et al. Long-lasting memory T cell responses following self-limited acute hepatitis B. F Clin Invest 1996;98:1185-94.

28 Dickson RC, Everhart JE, Lake JR, et al. Transmission of hepatitis $\mathrm{B}$ by transplantation of liver from donors positive for antibody to hepatitis B core antigen. Gastroenterology 1997;113:1668-74.

29 Shiratori Y, Shiina S, Imamura M, et al. Characteristic difference of hepatocellular carcinoma between hepatitis B and C viral infection in Japan. Hepatology 1995;22:1027-33.

30 Jilg W, Sieger E, Zachoval R, et al. Individuals with antibodies against hepatitis B core antigen as the only serological marker for hepatitis $\mathrm{B}$ infection: high percentage of carriers of hepatitis B and C virus. F Hepatol 1995;23:14-20.

31 Hoofnagle JH, Gerety RJ, Louisa YN, et al. Antibody to hepatitis B core antigen. N Engl f Med 1974;290:1336-40.

32 Pontisso P, Ruvoletto MG, Fattovich G, et al. Clinical and virological profiles in patients with multiple hepatitis virus infection. Gastroenterology 1993;105:1529-33.

33 Tanaka K, Hirohata T, koga S, et al. Hepatitis C and hepatitis B in the etiology of hepatocellular carcinoma in the apanese population. Cancer Res 1991;51:2842-7.

34 Shih CM, Lo SJ, Miyamura T, et al. Suppression of hepatitis $B$ virus expression and replication by hepatitis $C$ virus core protein in Huh7 cells. $\mathcal{F}$ Virol 1993;67:5823-32. 